\title{
Malaria Epidemiology and Control in Southern Africa
}

\section{Sungano Mharakurwa ${ }^{a, b}$, Philip E. Thuma ${ }^{a, b}$, Douglas E. Norris ${ }^{a}$, Modest Mulenga ${ }^{c}$, Victor Chalwe $^{\mathrm{c}}$, James Chipeta ${ }^{\mathrm{d}}$, Shungu Munyati ${ }^{\mathrm{e}}$, Susan Mutambu ${ }^{f}$, and Peter R. Mason ${ }^{\mathrm{e}}$ for the Southern Africa ICEMR Team}

Sungano Mharakurwa: smharaku@jhsph.edu; Philip E. Thuma: phil.thuma@macharesearch.org; Modest Mulenga: MulengaM@tdrc.org.zm; Victor Chalwe: victorchalwe@yahoo.com; James Chipeta: jameschipeta@smuth-mru.org.zm; Shungu Munyati: smunyati@brti.co.zw; Susan Mutambu: mutambu@hotmail.com; Peter R. Mason: pmason@brti.co.zw aJohns Hopkins Malaria Research Institute, Bloomberg School of Public Health, Johns Hopkins University, 615 North Wolfe Street, Baltimore, MD, 21205 USA

bMacha Research Trust, Namwala Road, PO Box 630166, Choma, Zambia

'Tropical Diseases Research Center, Ndola Central Hospital, Nkana Road and Broadway, PO Box 71769, Ndola, Zambia

dUniversity of Zambia School of Medicine, Department of Paediatrics and Child Health, PO Box 50110, Lusaka, Zambia

eBiomedical Research and Training Institute, Nicoz Diamond House, South Machel and Park Street, PO Box CY1753, Harare, Zimbabwe

${ }^{f}$ National Institute of Health Research, P.O. Box 573, Harare, Zimbabwe

\section{Abstract}

The burden of malaria has decreased dramatically within the past several years in parts of subSaharan Africa, following the scale-up of interventions supported by the Roll Back Malaria Partnership, the President's Malaria Initiative and other partners. It is important to appreciate that the reductions in malaria have not been uniform between and within countries, with some areas experiencing resurgence instead. Furthermore, while interventions have greatly reduced the burden of malaria in many countries, it is also recognized that the malaria decline pre-dated widespread intervention efforts, at least in some cases where data are available. This raises more questions as what other factors may have been contributing to the reduction in malaria transmission and to what extent. The International Center of Excellence for Malaria Research (ICEMR) in Southern Africa aims to better understand the underlying malaria epidemiology, vector ecology and parasite genomics using three contrasting settings of malaria transmission in Zambia and Zimbabwe: an area of successful malaria control, an area of resurgent malaria and an area where interventions have not been effective. The Southern Africa ICEMR will capitalize on the opportunity to investigate the complexities of malaria transmission while adapting to intervention and establish the evidence-base to guide effective and sustainable malaria intervention strategies. Key

(C) 2011 Elsevier B.V. All rights reserved.

Corresponding Author: Sungano Mharakurwa, Ph D, Scientific Director, Macha Research Trust, P.O. Box 630166, Choma, Zambia, smharaku@jhsph.edu.

The Southern Africa ICEMR team also includes the following individuals: Johns Hopkins Malaria Research Institute: Peter Agre, Gregory Glass, Andre Hackman, Tamaki Kobayashi, Thomas A. Louis, William J. Moss, Alan Scott, Timothy Shields and Clive Shiff; Biomedical Research and Training Institute: Lovemore Gwanzura; University of the Witwatersrand: Maureen Coetzee.

Conflict of Interest: None of the authors have a conflict of interest to disclose.

Publisher's Disclaimer: This is a PDF file of an unedited manuscript that has been accepted for publication. As a service to our customers we are providing this early version of the manuscript. The manuscript will undergo copyediting, typesetting, and review of the resulting proof before it is published in its final citable form. Please note that during the production process errors may be discovered which could affect the content, and all legal disclaimers that apply to the journal pertain. 
approaches to attaining this goal for the region will include close collaboration with national malaria control programmes and contribution to capacity building at the individual, institutional and national levels.

\section{Keywords}

malaria; epidemiology; transmission; control; prevalence; burden; Zambia; Zimbabwe

\subsection{Introduction}

Declines in the burden of malaria have been reported throughout sub-Saharan Africa (O’Meara WP, Mangeni JN 2010), following the scale-up of interventions under the Roll Back Malaria Partnership, the President's Malaria Initiative (PMI) and other renewed public-private partnerships. Albeit the interventions have greatly reduced malaria burden of many countries it is recognized that the malaria decline has not been universal, both interand intra-country (DaSilva J, Garanganga B 2004)(O'Meara WP, Mangeni JN 2010). Within Southern Africa, such wide heterogeneity that now exists in the burden of malaria despite implementation of control measures is of critical importance to success of the regional scaleup and elimination efforts. Research to understand the underlying reasons for sustained malaria depletion in some areas and why apparently the same interventions have not worked in other epidemiological settings is vital to extending locally tailored malaria control efforts, developing new control strategies and achieving malaria elimination in Southern Africa.

It has also been acknowledged that the observed malaria declines in some cases pre-dated the widespread intervention efforts, at least in several situations where data are available, (O'Meara WP, Bejon P 2008). This suggests the cautionary possibility of other as yet uncharacterized factors having been at play in the reduction of malaria transmission. Integrated research to ascertain what such factors may be, their relative contribution and dynamics, is imperative to ensure viability and effective timing of malaria control and elimination efforts.

The International Center of Excellence for Malaria Research (ICEMR) in southern Africa aims to better understand over time the underpinning malaria epidemiology, vector biology and parasite genomics in three contrasting epidemiological settings of malaria transmission in Zambia and Zimbabwe: an area of successful control (Choma District, Zambia), an area of resurgent malaria (Mutasa District, Zimbabwe) and an area where control interventions have been ineffective (Nchelenge District, Zambia) (Figure 1).

\subsection{Roll Back Malaria Efforts}

Zambia and Zimbabwe have a history of malaria control dating back to the 1940's (Sharp B, van Wyk P 2002;Mabaso ML, Sharp B 2004). By the mid-1980's, indoor residual spraying (IRS) in Zambia, previously effective in urban areas along the rail line from Chililabombwe to Livingstone, had become decentralized and subsequently declined (Sharp et al., 2002) as the economy weakened. This breakdown in the malaria control program was accompanied by a temporary resurgence in malaria, with incidence tripling over a 24 year period between 1970 and 2000 (Anon, 2000) and continuing to increase several years afterwards (Anon, 2003). Since Zambia was by then relying on case management at rural health centers as the sole method for malaria control, the increased prevalence of chloroquine resistance further hindered malaria control efforts (Bruce-Chwatt LJ 1978;Perry KR, Hone NM 1984;Wood R 1984)(Anon, 1996; Trape, 2001). 
Zambia revitalized its malaria control program under the guidance of the World Health Organization (WHO) Roll Back Malaria Partnership starting in the late 1990's (Hamer DH, Ndhlovu M 2007; Chanda E, Masaninga F 2008). With funding from the Global Fund to Fight AIDS, Tuberculosis and Malaria, the World Bank, PMI and other donors (Singer E 2005), Zambia made progress in malaria control, with dramatic declines in malaria incidence in many parts of the country (Ministry of Health Government of the Republic of Zambia 2010). The prevalence of malaria parasitemia in children younger than five years of age decreased 53\% from a baseline prevalence of 22\% between 2006 and 2008 (ChizemaKawesha E, Miller JM 2010).

The same cannot yet be said for Zimbabwe, where despite some funding for malaria control from the Global Fund, PMI and others, malaria remains a major cause of morbidity and mortality. Resistance of Plasmodium falciparum to chloroquine and sulfadoxinepyrimethamine (Mharakurwa and Mugochi, 1994a, b; Mharakurwa et al., 1998)(Mlambo, Sullivan 2007) and of Anopheles arabiensis to pyrethroids (Munhenga G, Masendu HT 2008) emerged, complicating malaria control. Both Zambia and Zimbabwe established national malaria control programs but these programs have been funded at a higher level in Zambia than in Zimbabwe in recent years. The primary malaria control strategies in both countries are indoor residual spraying (IRS), distribution of insecticide treated nets (ITNs), active case management with artemisinin combination therapy (ACT) and concomitant accurate malaria detection by rapid diagnostic tests (RDTs). There is also use of intermittent presumptive therapy against malaria in pregnancy (IPTp).

\subsection{Successful malaria control}

Choma District (Figure 1) has a population of 204,898 and is located in the Southern Province of Zambia, a drought-prone region that receives the lowest mean annual rainfall $(650-800 \mathrm{~mm})$ in the country(BÄUMLE et al., 2007). The area is characterized by cool (May - July) and hot (August - October) dry periods, with an unpredictable wet season between November and April. Malaria transmission is mainly by Anopheles arabiensis, with smaller foci of An. funestus and is highly seasonal, with little or none during the dry period.

The Southern Province has experienced a substantial decline in the burden of malaria (Ministry of Health Government of the Republic of Zambia 2010). The prevalence of parasitemia in children younger than five years of age residing in Southern Province was 13.7\% according to the 2006 National Malaria Indicator Survey (Ministry of Health Government of the Republic of Zambia 2006), decreased almost half to $7.9 \%$ by 2008 (Ministry of Health Goverment of the Republic of Zambia 2008), and was 5.7\% (by microscopy) in 2010 (Ministry of Health Government of the Republic of Zambia 2010), making Southern Province one of the provinces with the lowest parasite prevalence in Zambia, behind Lusaka (0\%) and Western Provinces (5.1\%).

Prior to 2003 the number of cases of malaria were increasing in Choma District (National Malaria Control Centre 2003), but following the introduction of ACTs a dramatic decline in malaria was observed. Data on confirmed malaria cases in children from Macha Hospital shows an association between the start of ACT implementation and a decline in the number of children hospitalized with malaria (Figure 2), with a rebound in the number of hospitalized children with malaria when ACT was temporarily unavailable. This decline in pediatric admissions for malaria preceded widespread distribution of insecticide-treated nets in the region. Extended drought conditions in southern Africa in 2004-2005 led to a concurrent decline in the population density of Anopheles arabiensis mosquitoes and the near eradication of An. funestus (Kent RJ, Mharakurwa S 2007;Kent RJ, Thuma PE 2007), likely contributing to the decline in pediatric hospitalizations for malaria. 


\subsection{Resurgent malaria after previous control}

Mutasa District has a population of 180,454 (according to the 2010 census) and is located in a mountainous area of the Manicaland Province of Zimbabwe. The altitude ranges from less than 600 - more than 1600 meters above sea level. The low-lying part of the district with valleys of the Honde and Pungwe rivers averages $900 \mathrm{~m}$ above sea level and is endemic for malaria. Called the Honde Valley, this lower section of Mutasa district is an area of farmland on the eastern border of Zimbabwe with Mozambique, and is the location of several large tea estates. Workers on the estates live in compounds consisting of small housing communities, but much of the area consists of small-scale subsistence farms characterized by small villages. In general, the village settlements are concentrated along perennial streams, and on hillsides endowed with arable soils. While the streams, emanating from the surrounding mountains flow throughout the year, Honde Valley does experience cool (May - July) and hot (August - October) dry periods, with a rainy season during the period November - April. By contrast to the Zambian sites, malaria transmission is seasonal, unstable and epidemic in nature, exacting morbidity and mortality across all ages(Lukwa et al., 1999; Mharakurwa et al., 1997; Mharakurwa et al., 2004). The responsible vector mosquito species in this valley of tea plantations and jungle-like vegetation that is atypical of Zimbabwe and remains unclear. Mutasa district was under effective malaria control as part of the Zimbabwean Ministry of Health integrated malaria control program that began in the early 1950's and expanded in the 1980's (Taylor P and Mutambu SL 1986)(Taylor and A., 1988). Financial constraints militated against this program from the mid to late-1990s, leading to decentralization of IRS activities and temporary exclusion of Mutasa and other areas from IRS coverage, as part of "selective control" to minimize cost of insecticide(Mharakurwa et al., 2004). The district continues to experience a resurgence of malaria, albeit IRS, ITNs and ACT interventions have been implemented since 2007(Lewis and Hamade, 2008).

Mutasa District is served by two district hospitals, Bonda Mission Hospital and Hauna District Hospital, and 14 clinics or health centers. Malaria has been the most common reason for presentation at health centers in Mutasa District, with an overall relative risk four times higher than that of acute respiratory infections, the next most common diagnosis. The number of reported cases of malaria for all ages increased in Mutasa District over the past decade (Figure 3). In 1995, the number of cases of clinical malaria was 22,834. Between 1995 and 2005 the annual number of reported cases ranged from 19,883 (in 2002) and 67,978 (in 1998). However, the number of reported cases of clinical malaria rose to 75,510 in 2006 and peaked at 75,844 in 2007 . The age distribution of cases that spans all ages presumably reflects previous successful malaria control for decades, characterized by little or no acquired immunity in the resident population. There is some degree of population movement in and out of the valley to seek employment, and small numbers of communities cross from Mozambique to seek medical care at few health centres near the border. However, this has remained constant and would not account for the substantial malaria upsurge in the Honde valley.

The national malaria incidence rate in 2007 declined only $7.4 \%$ from the incidence of 136 cases per 1,000 persons in 2000, and the number of cases of clinical malaria reported annually did not change since 1996, ranging from approximately 1.5 million to 1.8 million cases per year(Lewis and Hamade, 2008).

\subsection{Ineffective malaria control}

Nchelenge District, in Luapula Province of Zambia, lies in a high rainfall belt of the Central Africa plateau. The district, which has a population of 137,000, is located to the northeast of 
Ndola in the marshlands of the Luapula River and the environs of Lake Mweru, which it shares with the Democratic Republic of the Congo (DRC) along the border. Population movement across the border to and from the DRC is common. The ecology in the vicinity of Lake Mweru and the agricultural practices in the area are typical habitats for An. funestus as well as An. gambiae and An. arabiensis. Malaria transmission is intense with little or no seasonal fluctuations. Despite implementation of malaria control strategies, including IRS, ITN distribution and the use of ACT, malaria cases have not declined (Figure 4). Recent preliminary data from ICEMR baseline surveys show evidence of emerging An. gambiae ss resistance to pyrethroids and DDT. The prevalence of parasitemia in children younger than five years of age residing in Luapula Province was 32.9\% according to the 2006 National Malaria Indicator Survey and increased to $50.5 \%$ by the time of the 2010 survey, making Luapula the province with the highest parasite prevalence in Zambia, ahead of Northern Province (23.6\%) (Ministry of Health Government of the Republic of Zambia 2010).

\subsection{Response of National Malaria Control Programs}

In accordance with Roll Back Malaria initiatives, most sub-Saharan African countries used the opportunity to intensify malaria control efforts. The first major effort in Zambia was a change in drug policy in 2003 from chloroquine, to which Plasmodium falciparum was resistant, to artemether-lumefantrine as first line treatment (Sipilanyambe N, Simon JL 2008; Steketee RW, Sipilanyambe N 2008;Barnes KI, Chanda P 2009). This was followed by mass distribution of ITNs and selective IRS in urban and peri-urban areas (Steketee RW, Sipilanyambe N, Chimumbwa J, Banda JJ, Mohamed A, Miller J, Basu S, Miti SK, and Campbell CC 2008; Chizema-Kawesha E, Miller JM, Steketee RW, Mukonka VM, Mukuka C, Mohamed AD, Miti SK, and Campbell CC 2010). While these efforts resulted in a decline in malaria transmission in many areas of Zambia, there remains a heavy burden of malaria in some districts, particularly Luapula and Northern Provinces. Zimbabwe has also received some funding for malaria control but the burden of malaria has increased in many parts of the country, requiring a renewed effort to bring it under control again.

\subsection{Malaria and Malaria Control in Southern Africa}

Three contrasting malaria epidemiological settings are apparent within the southern African region notwithstanding the scale-up of interventions. Research to elucidate the underlying vector ecology, epidemiology and parasite genomic diversity in these contrasting areas where malaria transmission is unchanged, resurgent or on the decline will help provide an evidence base to better guide and focus control programs and policy in the region. Work to characterize the vector ecology and behavior and P. falciparum distribution, multiplicity of infection, genetic profiles and spatial distribution of cases in these contrasting areas would aid in formulation of locally tailored strategies to improve control and eventual elimination.

However, as evident both in the area of successful control in Zambia and other regions elsewhere, malaria decline appeared to have started before scaled up of interventions. Thus, there remains concern about whether current scaled-up of interventions against malaria are the only, or indeed the main, factor leading to the decline in malaria. Longitudinal studies in the ecological, vector and parasite genetic diversity in these contrasting transmission areas will go some way towards answering such critical questions urgently needed to ensure the successes are not transient, as in the previous malaria eradication era. Such an event would threaten the credibility of the battle against malaria and may well deal a final blow to the delicate balance of donor support, pharmaceutical/pesticide company interest, strong political commitment and a concomitant structure of trained endemic country scientists and control program implementers. This renewed interest by all parties took decades to come together. Research such as afforded through the ICEMR will be important in contributing 
evidence for safeguarding improvement and success in malaria control and its eventual elimination.

\section{Acknowledgments}

Role of the funding source: This work was supported by the Division of Microbiology and Infectious Diseases, National Institutes of Allergy and Infectious Diseases, National Institutes of Health. The sponsor requested submission of this paper but had no role in the writing of the report.

We are grateful to the district health teams of Choma, Nchelenge and Mutasa Districts and the Ministries of Health of Zambia and Zimbabwe for access to health center data. We wish to thank Professor Simon Gregson, Dr. Constance Nyamukapa, Edith Mpandaguta and the Manicaland HIV Prevention team for facilitating initial contact with Mutasa District and Manicaland Provincial Health authorities.

\section{Non-Standard Abbreviations}

ICEMR International Centers of Excellence for Malaria Research

\section{References}

Malaria in Zambia. Situation analysis May 2000. National Malaria Control Centre, Central Board of Health; Zambia Lusaka: 2000.

Malaria Situation Analysis of Zambia. National Malaria Control Centre; Zambia, Lusaka: 2003.

A Brief Report on the Chloroquine Sensitivity Studies carried out in Zambia in Nine Districts between May 1995 and May 1996: National Malaria Control and Research Centre. Ministry of Health; Lusaka: 1996.

Barnes KI, Chanda P, Barnabas GA. Impact of the large-scale deployment of artemether/lumefantrine on the malaria disease burden in Africa: case studies of South Africa, Zambia and Ethiopia. Malar J. 2009; 8(Suppl 1):S8. [PubMed: 19818175]

Baumle, R.; Nkhoma, J.; Silembo, O. Hydrogeological Map of Zambia, Southern Province: Map Sheet Kafue Flats and Southern Tributaries 1:250,000. 1. Lusaka, editor. Hannover: Department of Water Affairs (DWA), Zambia \& Federal Institute for Geosciences and Natural Resources (BGR); 2007.

Bruce-Chwatt LJ. Chloroquine resistance in Zambia. Br Med J. 1978; 2:206. [PubMed: 354744]

Chanda E, Masaninga F, Coleman M, Sikaala C, Katebe C, Macdonald M, Baboo KS, Govere J, Manga L. Integrated vector management: the Zambian experience. Malar J. 2008; 7:164. [PubMed: 18752658]

Chizema-Kawesha E, Miller JM, Steketee RW, Mukonka VM, Mukuka C, Mohamed AD, Miti SK, Campbell CC. Scaling up malaria control in Zambia: progress and impact 2005-2008. Am J Trop Med Hyg. 2010; 83:480-488. [PubMed: 20810807]

DaSilva J, Garanganga B, Teveredzi V, Marx SM, Mason SJ, Connor SJ. Improving epidemic malaria planning, preparedness and response in Southern Africa. Report on the 1st Southern African Regional Epidemic Outlook Forum, Harare, Zimbabwe, 26-29 September, 2004. Malar J. 2004; 3:37. [PubMed: 15500683]

Hamer DH, Ndhlovu M, Zurovac D, Fox M, Yeboah-Antwi K, Chanda P, Sipilinyambe N, Simon JL, Snow RW. Improved diagnostic testing and malaria treatment practices in Zambia. JAMA. 2007; 297:2227-2231. [PubMed: 17519412]

Kent RJ, Mharakurwa S, Norris DE. Spatial and temporal genetic structure of Anopheles arabiensis in Southern Zambia over consecutive wet and drought years. Am J Trop Med Hyg. 2007; 77:316323. [PubMed: 17690405]

Kent RJ, Thuma PE, Mharakurwa S, Norris DE. Seasonality, blood feeding behavior, and transmission of Plasmodium falciparum by Anopheles arabiensis after an extended drought in southern Zambia. Am J Trop Med Hyg. 2007; 76:267-274. [PubMed: 17297034]

Lewis, R.; Hamade, P. Roll Back Malaria: country needs assessment Zimbabwe report. 2008. 
Lukwa N, Nyazema NZ, Curtis CF, Mwaiko GL, Chandiwana SK. People's perceptions about malaria transmission and control using mosquito repellent plants in a locality in Zimbabwe. Cent Afr J Med. 1999; 45:64-68. [PubMed: 10565064]

Mabaso ML, Sharp B, Lengeler C. Historical review of malarial control in southern African with emphasis on the use of indoor residual house-spraying. Trop Med Int Health. 2004; 9:846-856. [PubMed: 15303988]

Mharakurwa S, Manyame B, Shiff CJ. Trial of the ParaSight-F test for malaria diagnosis in the primary health care system, Zimbabwe. Trop Med Int Health. 1997; 2:544-550. [PubMed: 9236821]

Mharakurwa S, Mugochi T. Chloroquine-resistant falciparum malaria in an area of rising endemicity in Zimbabwe. J Trop Med Hyg. 1994a; 97:39-45. [PubMed: 8107172]

Mharakurwa S, Mugochi T. Response of chloroquine-resistant falciparum malaria to sulfadoxine/ pyrimethamine in Gokwe area of Zimbabwe. Cent Afr J Med. 1994b; 40:53-56. [PubMed: 7923343]

Mharakurwa S, Mutambu SL, Mudyiradima R, Chimbadzwa T, Chandiwana SK, Day KP. Association of house spraying with suppressed levels of drug resistance in Zimbabwe. Malar J. 2004; 3:35. [PubMed: 15491495]

Mharakurwa S, Rangarira R, Murahwa FC, Chandiwana SK. Status of chloroquine efficacy against falciparum malaria in the Mola area of Kariba district, Zimbabwe. Ann Trop Med Parasitol. 1998; 92:655-661. [PubMed: 9924544]

Ministry of Health Goverment of the Republic of Zambia. 2008 Zambia National Malaria Indicator Survey. 2008.

Ministry of Health Government of the Republic of Zambia. 2006 Zambia National Malaria Indicator Survey. 2006.

Ministry of Health Government of the Republic of Zambia. 2010 Zambia National Malaria Indicator Survey. 2010.

Mlambo G, Sullivan D, Mutambu SL, Soko W, Mbedzi J, Chivenga J, Gemperli A, Kumar N. High prevalence of molecular markers for resistance to chloroquine and pyrimethamine in Plasmodium falciparum from Zimbabwe. Parasitol Res. 2007; 101:1147-1151. [PubMed: 17546463]

Munhenga G, Masendu HT, Brooke BD, Hunt RH, Koekemoer LK. Pyrethroid resistance in the major malaria vector Anopheles arabiensis from Gwave, a malaria-endemic area in Zimbabwe. Malar J. 2008; 7:247. [PubMed: 19038063]

National Malaria Control Centre. 2003 Malaria situation analysis of Zambia.

O’Meara WP, Bejon P, Mwangi TW, Okiro EA, Peshu N, Snow RW, Newton CR, Marsh K. Effect of a fall in malaria transmission on morbidity and mortality in Kilifi, Kenya. Lancet. 2008; 372:1555-1562. [PubMed: 18984188]

O’Meara WP, Mangeni JN, Steketee R, Greenwood B. Changes in the burden of malaria in subSaharan Africa. Lancet Infect Dis. 2010; 10:545-555. [PubMed: 20637696]

Perry KR, Hone NM, Cairns JM. Chloroquine resistant Plasmodium falciparum malaria confirmed by in-vitro testing in a district hospital. Med J Zambia. 1984; 18:8-9. [PubMed: 6398566]

Sharp B, van Wyk P, Sikasote JB, Banda P, Kleinschmidt I. Malaria control by residual insecticide spraying in Chingola and Chililabombwe, Copperbelt Province, Zambia. Trop Med Int Health. 2002; 7:732-736. [PubMed: 12225502]

Singer E. International partnership launches malaria model in Zambia. Nat Med. 2005; 11:695. [PubMed: 16015341]

Sipilanyambe N, Simon JL, Chanda P, Olumese P, Snow RW, Hamer DH. From chloroquine to artemether-lumefantrine: the process of drug policy change in Zambia. Malar J. 2008; 7:25. [PubMed: 18230140]

Steketee RW, Sipilanyambe N, Chimumbwa J, Banda JJ, Mohamed A, Miller J, Basu S, Miti SK, Campbell CC. National malaria control and scaling up for impact: the Zambia experience through 2006. Am J Trop Med Hyg. 2008; 79:45-52. [PubMed: 18606763]

Taylor P, Mutambu SL. A review of the malaria situation in Zimbabwe with special reference to the period 1972-1981. Trans R Soc Trop Med Hyg. 1986; 80:12-19. [PubMed: 3523860] 
Taylor, P.; Taputaira, A. Forty years of malaria control in Zimbabwe. Proceedings of the First National Symposium of Science and Technology; Harare. 1988.

Trape JF. The public health impact of chloroquine resistance in Africa. Am J Trop Med Hyg. 2001; 64:12-17. [PubMed: 11425173]

Wood R. Chloroquine resistant Plasmodium falciparum malaria confirmed by in vivo testing in Lusaka. Med J Zambia. 1984; 18:5-6. [PubMed: 6400678] 


\section{Research Highlights}

- Zambia and Zimbabwe have a long history of malaria control efforts

- The burden of malaria has decreased dramatically in much of Zambia due to accelerated malaria control efforts

- Despite implementation of malaria control strategies, heterogeneity in the burden of malaria exists

- The goal of the Southern Africa International Center of Excellence for Malaria Research is to better understand this heterogeneity and further malaria control 


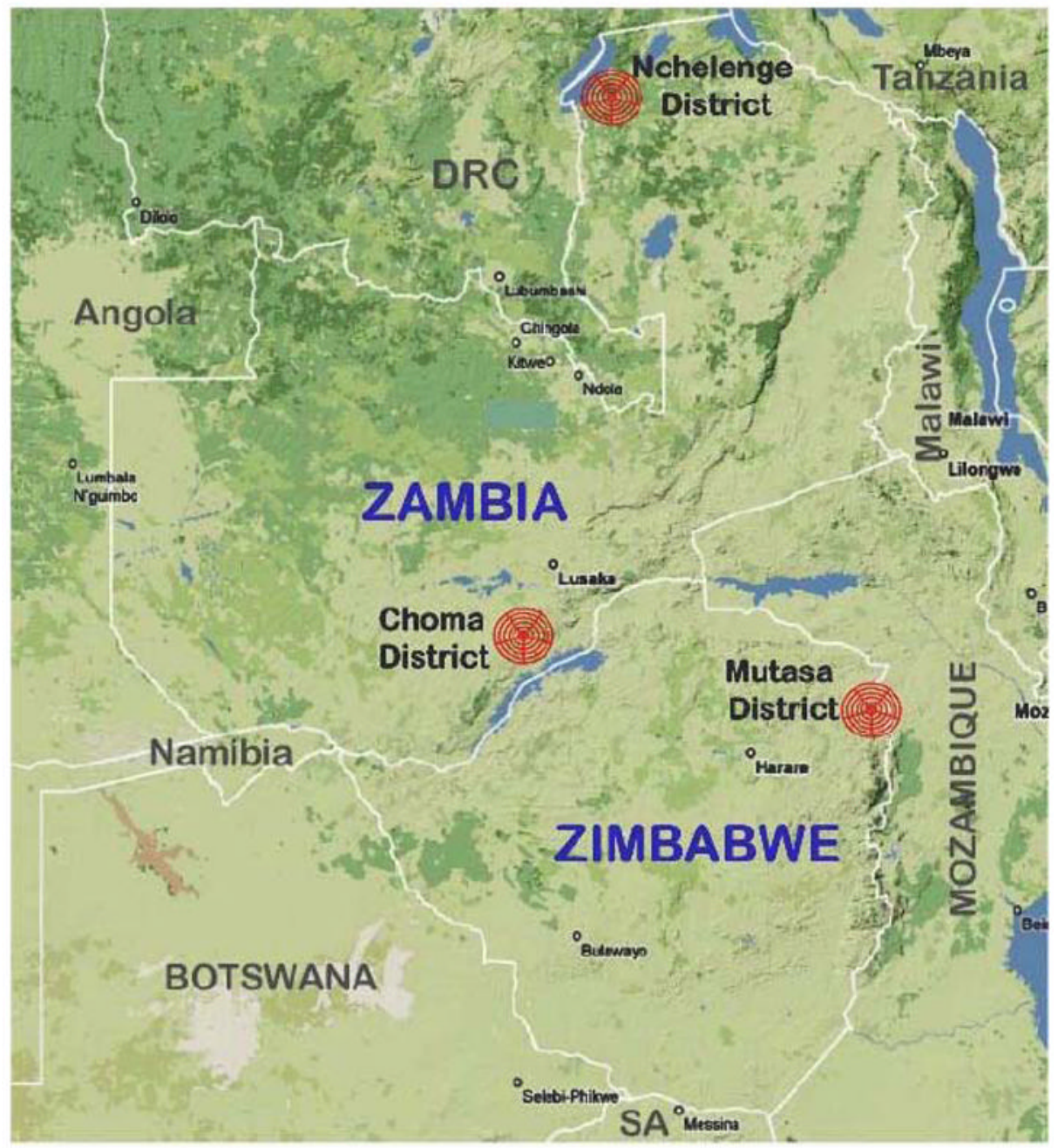

Figure 1.

Location of study sites representing three distinct regions of malaria transmission and control: Choma District, Zamiba (successful control); Nchelenge District, Zambia (ineffective control); and Mutasa District, Zimbabwe (formerly successful control but now resurgent malaria area), 


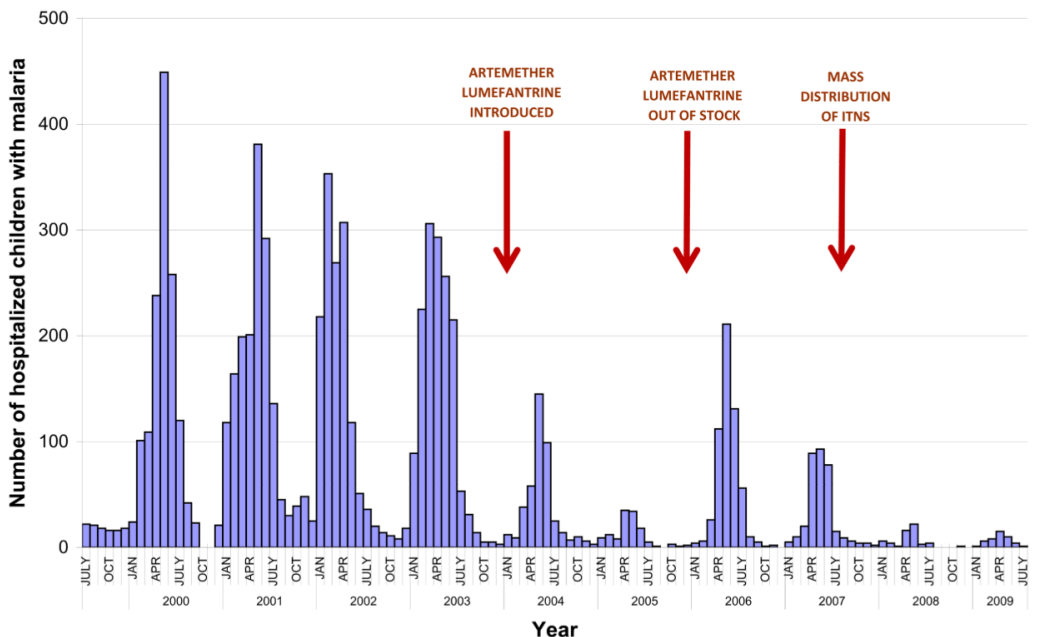

Figure 2.

Pediatric hospitalizations for malaria at Macha Hospital, Zambia. Red arrows indicate the introduction of malaria control interventions and the unavailability of Coartem (artemetherlumefantrine). Macha Hospital data compiled by Dr. Phil Thuma. 


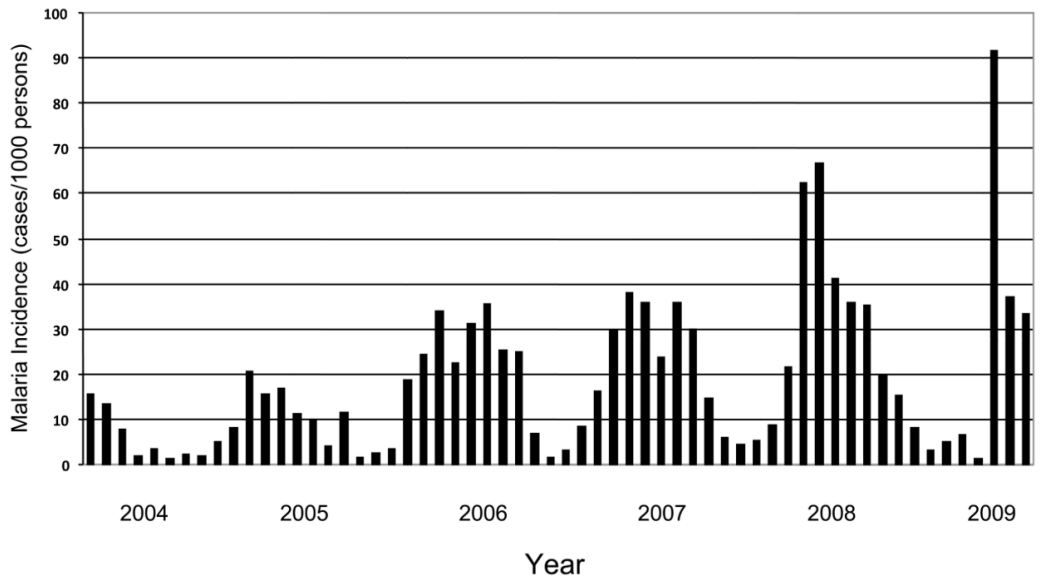

Figure 3.

Malaria incidence per 1000 persons for Mutasa District, Zimbabwe. Data courtesy of the Ministry of Health and Child Welfare, Zimbabwe. 


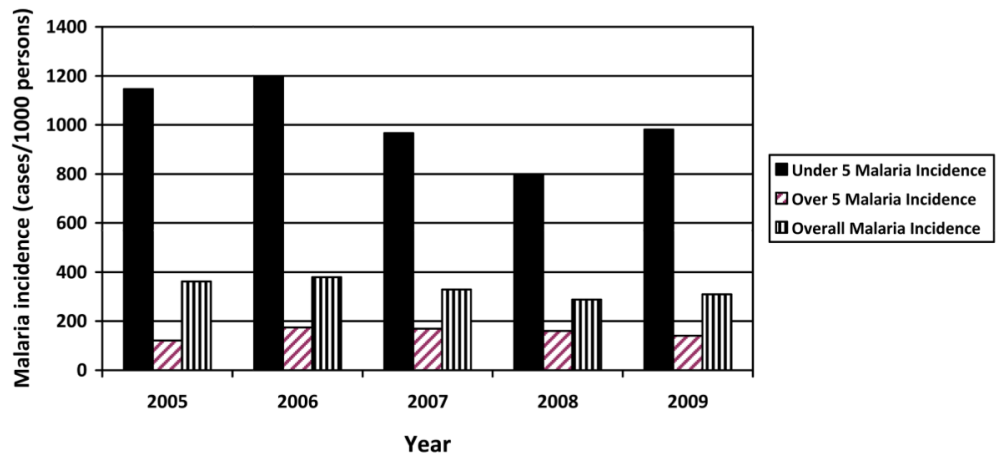

Figure 4.

Malaria incidence per 1000 persons for Nchelenge District, Zambia. Data courtesy of the Nchelenge District Health Office, Ministry of Health, Zambia. 